\title{
Building the Evidence Base to Prevent Firearm Deaths and Injuries
}

\author{
David Vlahov
}

Published online: 4 June 2018

(C) The New York Academy of Medicine 2018

This week as we go to press, a 17-year-old gunman fired on and killed 10 people at the Santa Fe High School in Texas. We mourn and express our condolences to the relatives and friends whose loss is personal and to communities whose trauma is collective.

This episode follows the February rampage at the Marjory Stoneman Douglas High School in Parkland, Florida, where a 19-year-old gunman killed 17 people. Since the beginning of 2018, there have been 10 school shootings and 101 mass shootings involving four or more people. Excluding suicide, the Gun Violence Archive recorded 15,549 firearm-related deaths in 2017. Including suicide, the most recent available federal data reported 38,658 firearm-related deaths in 2016.

Data are sparse on how to prevent firearm deaths and injuries. There have been no government-sponsored studies on this since 1996, when the Dickey amendment was added to a US House of Representatives bill. The amendment stated that the CDC may not conduct any studies that "advocate or promote gun control." In 2012, that prohibition was expanded to the entire Department of Health and Human Services.

The restriction on research means that it has been difficult to objectively evaluate the potential efficacy of any proposed gun control laws. In 2003, when the Task Force on Community Preventive Services issued its first report evaluating the effectiveness of strategies to

D. Vlahov $(\bowtie)$

Yale School of Nursing, Orange, CT, USA

e-mail:dvlahov@me.com prevent violence, it concluded that there was insufficient evidence to make any determination [1].

In an effort to change the dynamic after the Sandy Hook Elementary School massacre, which took place in Newtown, Connecticut, in December 2012, Vice President Biden called for the Institute of Medicine to conduct a review and provide a report on firearm-related research. The report Priorities for Research to Reduce the Threat of Firearm-Related Violence was published in 2013 [2]. It highlighted significant gaps in knowledge to formulate prevention strategies and proposed a research agenda-designed to produce results in three to five years - which focuses on the characteristics of firearm violence, risk and protective factors, interventions and strategies, the impact of gun safety technology, and the potential influence of video games and other media. Yet with Congress stalled on providing funding, the research has lagged, although some private foundations have stepped forward.

Recently, the governors of six states (Connecticut, Delaware, Massachusetts, New Jersey, New York, Rhode Island) and Puerto Rico have launched a gun violence research consortium, bypassing Congress. With 44 experts in criminology, medicine, and public health, we may expect research in the coming months and years.

In this issue of the Journal of Urban Health, we publish eight original data reports from expert researchers around the country. All of the studies speak to our current circumstances. For example, the shooter at the Santa Fe, Texas high school used guns registered to his father. In this issue, Azrael et al. report from a 
nationally representative probability-based online survey of 3949 U.S. adults in 2015 and noted that one in three households owns a gun and of those gun-owning homes with children, only $30 \%$ stored their guns safely [3].

Even in the absence of all the necessary research, there are some commonsense approaches clinicians should be able to bring to their patient encounters. In 2015 , at least 265 children under 18 years old picked up a firearm and shot someone by accident; 83 of those incidents were fatal, and about half of the fatalities were the children themselves [4]. Given the public health costs, we should be able to have conversations about gun safety with our patients. In 2017, the U.S. Court of Appeals for the 11th Circuit issued its ruling in the Wollschlaeger v. Governor, State of Florida, that invalidated parts of the Florida's Firearm Owner's Privacy Act that had been a gag order on physicians about raising and discussing gun safety with their patients [5]. Health care providers can ask about and educate about gun safety with their patients.

We owe a debt of gratitude to the students of the Marjory Stoneman Douglas High School in Parkland, Florida. Their voices have moved the legislature in Florida to begin enacting laws, have mobilized thousands around the world to March for Our Lives, and have brought together six governors to create a research consortium that will move forward to generate evidence to prevent firearm deaths and injuries. At the Journal, we owe a debt as well as this issue is dedicated to their work for our lives.

\section{References}

1. Hahn RA, Bilukha OO, Crosby A, Fullilove MT, Liberman A, Moscicki EK, et al. First reports evaluating the effectiveness of strategies for preventing violence: firearm laws. Findings from the Task Force on Community Preventive Services. MMWR Recomm Rep. 2003;52(RR-14):11-20.

2. Institute of Medicine. Priorities for research to reduce the threat of firearm-related violence. Washington, D.C.: National Academy Press; 2013.

3. Azrael D, Cohen J, Salhi C, Miller M. Firearm storage in gunowning households with children: results of a 2015 national survey. J Urban Health. 2018;

4. https://everytownresearch.org/notanaccident (accessed 05/21 /2018)

5. Parmet WE, Smith JA, Miller M. Physicians, firearms and free speech - overturning Florida's firearm safety gag rule. $N$ Engl J Med. 2017;376:1901-3. 